\title{
Health professions and risk of sporadic Creutzfeldt- Jakob disease, 1965 to 2010
}

E Alcalde-Cabero ${ }^{1}$, J Almazán-Isla ${ }^{1}$, J P Brandel ${ }^{2}$, M Breithaupt ${ }^{3}$, J Catarino4, S Collins 5 , J Haybäck 6 , R Höftberger7, E Kahana ${ }^{8}$, G G

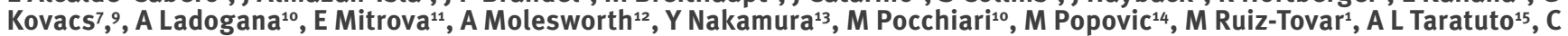
van Duijn ${ }^{16}$, M Yamada ${ }^{17}$, R G Will ${ }^{12}$, I Zerr 3 , J de Pedro Cuesta (jpedro@isciii.es) ${ }^{1}$

1. National Centre of Epidemiology - Consortium for Biomedical Research in Neurodegenerative Diseases (Centro de Investigación Biomédica en Red sobre Enfermedades Neurodegenerativas - CIBERNED), Carlos III Institute of Health, Madrid, Spain

2. Institut National de la Santé et de la Recherche Médicale (INSERM) UMRS 975, National CJD Surveillance Network, Assistance publique - Hôpitaux de Paris (APHP), National Reference Centre for CJD, Pitié-Salpêtrière Hospital Group, Paris, France

3. Department of Neurology, National Reference Centre for TSE, Georg-August University, Göttingen, Germany

4. Alameda Epidemiology and Health Statistics Department, Lisbon, Portugal

5. Department of Pathology, University of Melbourne, Melbourne, Australia

6. Institute of Neuropathology, Zurich University Hospital, Zurich, Switzerland

7. Institute of Neurology, Vienna Medical University, Vienna, Austria

8. Department of Neurology, Barzilai Medical Centre, Ashkelon, Israel

9. National Reference Centre for Human Prion Diseases, Semmelweis University, Budapest, Hungary

10. Department of Cell Biology and Neurosciences, Health Institute, Rome, Italy

11. Department of Prion Diseases, Slovak Medical University Research Base, Bratislava, Slovakia

12. National CJD Research and Surveillance Unit, Western General Hospital, Edinburgh, United Kingdom

13. Department of Public Health, Jichi Medical University, Shimotsuke, Japan

14. nstitute of Pathology, Medical Faculty, University of Ljubljana, Ljubljana, Slovenia

15. Department of Neuropathology/FLENI, Referral Centre for CJD and other TSEs, Institute for Neurological Research, Buenos Aires, Argentina

16. National Surveillance of CJD, Erasmus MC, Rotterdam, The Netherlands

17. Neurology Department, Kanazawa University Hospital, Kanazawa, Japan

In 2009, a pathologist with sporadic CreutzfeldtJakob Disease (sCJD) was reported to the Spanish registry. This case prompted a request for information on health-related occupation in SCJD cases from countries participating in the European Creutzfeldt Jakob Disease Surveillance network (EuroCJD). Responses from registries in 21 countries revealed that of 8,321 registered cases, 65 physicians or dentists, two of whom were pathologists, and another 137 healthcare workers had been identified with SCJD. Five countries reported 15 physicians and 68 other health professionals among 2,968 controls or non-cases, suggesting no relative excess of SCJD among healthcare professionals. A literature review revealed: (i) 12 case or small case-series reports of 66 health professionals with sCJD, and (ii) five analytical studies on health-related occupation and SCJD, where statistically significant findings were solely observed for persons working at physicians' offices (odds ratio: 4.6 (95 Cl: 1.2-17.6)). We conclude that a wide spectrum of medical specialities and health professions are represented in SCJD cases and that the data analysed do not support any overall increased occupational risk for health professionals. Nevertheless, there may be a specific risk in some professions associated with direct contact with high human-infectivity tissue.

\section{Introduction}

Creutzfeldt-Jakob disease (CJD) is a fatal neurodegenerative disease characterised by deposition of a pathological isoform of the normal cellular prion protein $\left(\mathrm{PrP}^{\mathrm{C}}\right)$ [1]. The annual CJD incidence worldwide is 1-2 per million population [2]. CJD exists in various forms: genetic, caused by mutations in the PRNP gene encoding $\operatorname{PrP} \mathrm{P}^{\mathrm{C}}$, acquired (variant and iatrogenic) and sporadic. Most cases have sporadic CJD (sCJD) - the cause of which is unknown. Occupational risk related to SCJD has been assessed in several case-control studies as a secondary study objective, with inconsistent results [3-7] and there have been occasional reports of health professionals with SCJD [8-12].

Occupation has not been included as a variable in all CJD surveillance protocols [13]. Nonetheless, there is concern about potential occupational excess risk of sCJD among health professions, as shown by a recent study on guidelines in European Union (EU) Member States and Norway for the prevention of CJD transmission in medical settings. This study showed that 12 of the 17 contributing countries had specific recommendations targeted at minimising occupational exposure; 
eight of the 12 had systems for reporting or registering work-related incidents at hospitals or laboratories [14].

In March 2009, a CJD case was reported to the Spanish CJD registry, who was classified as having sporadic CJD. As the patient was an experienced general pathologist and neuropathologist, it was speculated that the disease might have been a result of the person's professional activities. The event was commented on in medical, scientific and mass media in Spain and elsewhere, e.g. [15]. The patient died after a four-month disease course, characterised mainly by cognitive decline, ataxia and myoclonus. The disease prion protein subtype, i.e. strain, was confirmed histochemically and biochemically as $M_{1}$, the most common subtype [2]. Risk factors for developing CJD, including blood transfusion, iatrogenic exposure (e.g. to dura mater, cadaveric pituitary-derived growth hormone) and mutations in the PRNP gene, were not identified. Assessment of the patient's routine hospital work indicated that the patient had had a history of minor injuries during postmortem examinations (personal communication, E. García-Albea, April 2009).

\section{Box}

Search terms used in first step of two literature searches on sporadic Creutzfeldt-Jakob disease (sCJD) in health professionals and analytical studies on occupational risk of sCJD for health professions and selection criteria used in a second step, reported 1 January 1989-1 October 2011

\section{MEDLINE}

The search strategy was based on the following medical subject headings $(\mathrm{MeSH})$ terms:

- prion diseases/prions/Creutzfeldt-Jakob syndrome; and

- health occupations/allied health occupations/ occupational groups/occupations/occupational dentistry/case control studies.

\section{Embase}

The search strategy was based on the following Emtree thesaurus terms:

- prion/prion disease/prion protein/Creutzfeldt Jakob disease/ Creutzfeldt Jakob disease agent; and

- occupation/occupation and occupation-related phenomena/ medical profession/nursing as a profession/nursing career/paramedical profession/professional development/ occupational accident/occupation and occupation-related phenomena/occupational accident/occupational disease/ occupational exposure/occupational hazard/occupational health/occupational health nursing/occupational health service/occupational medicine/occupational physician/ occupational safety/occupational therapist.

Selection criteria

\section{Inclusion}

Either specific reference to the subject (Creutzfeldt-Jakob disease and health profession) or analytical study design (either case-control or cohort), regardless of the study's stated objective.

\section{Exclusion}

Identification of the document as a letter or review, news, comment, congress abstract, when reference to health professions was not explicitly made.
Following notification of this patient, the Spanish registry circulated a request for information to each national surveillance team participating in the European Creutzfeldt Jakob Disease Surveillance Network (EuroCJD), which dates back to 1993 and currently encompasses 25 collaborating centres in EU Member States and European Free Trade Association (EFTA) countries and a further eight in countries around the world, including Australia, Canada and Japan [16]. These centres provide data from national registries either through the EuroCJD website or, as with Japanese data, at regular network meetings. The request asked for the following: (i) information on the diagnosis (year of birth and death, sex and place of residence) of reported cases of sporadic CJD among active or retired pathologists from 1996 onwards; and (ii) comments based on personal experience of occupational risk and CJD among health professionals, including technicians working at pathology laboratories.

There has been limited systematic research targeted at identifying occupational risk factors for SCJD in healthcare settings. This paper reports on the data supplied to the Spanish CJD registry in response to the request, and on the results of two literature reviews of SCJD one on case reports involving health professionals and the other on epidemiologically assessed healthcarerelated occupational risk of SCJD.

\section{Methods}

\section{Individualised occupational data from national CJD surveillance teams}

The Spanish CJD registry obtained answers in English to at least one of the requests for information from 21 national surveillance teams. The amount of information provided varied: in general, only data that had already been registered was reported; with regard to occupational history in CJD - recorded by profession or activity branch - several countries provided information on people in whom CJD had been excluded or on controls.

The data received were divided into two groups, for further analysis - one describing health professionals who were SCJD cases and the other describing health professionals among controls or non-cases. We did not attempt a formal epidemiological assessment of healthcare-related occupational risk of SCJD based on this information, for instance using a case-control design.

Case reports of SCJD among health professionals Countries with available registry data on cases' occupations sent individualised data on physicians with neuropathologically confirmed or probable SCJD or other types of CJD $[17,18]$. Some countries provided such data on other health professions. In the few instances in which occupation as a pathologist was identified, professional experience or job duration at a laboratory or department was specified. The results were tabulated, using the original definitions from the countries' 
reports. No standard occupational classification was used for grouping response results and each case was assigned to one occupational category. Frequently, the occupational categories corresponded to a combination of professional profiles, e.g. specialities and work types (clinical, administrative, laboratory, etc.). In such cases, the category most likely to involve direct contact with human tissue or patients was selected.

\section{Healthcare-related occupations among}

controls and non-cases

Some CJD surveillance teams with a sufficient sample size provided data on occupation of people with suspected SCJD who were finally classified as not having CJD (non-cases) and also of those in control groups. Five EuroCJD countries with large populations Germany, Italy, Japan, Spain and the United Kingdom (UK) - provided this type of data, both published and unpublished. These countries supplied data on physicians who were controls Italy and Japan also provided information on other health professionals who were non-cases. Information on different categories of health professionals was available for British controls. Occupation was usually categorised on the basis of original records at registries. In a few instances, reporting physicians or relatives were consulted about the predominant activity, e.g. general practice vs radiology, of the non-cases.

\section{Literature reviews}

The first step in the literature reviews sought to identify reports of SCJD among health professionals, whether reported as case studies or drawn from analytical studies published during 1 January 1989 to 1 October 2011. We carried out several searches in MEDLINE and Embase using the medical subject headings (MeSH) and Emtree thesaurus terms listed in the Box, to identify case studies on CJD in health professionals and

\section{FIGURE 1}

Literature review of case reports of sporadic Creutzfeldt-Jakob disease among health professionals, 1979-1 October 2011

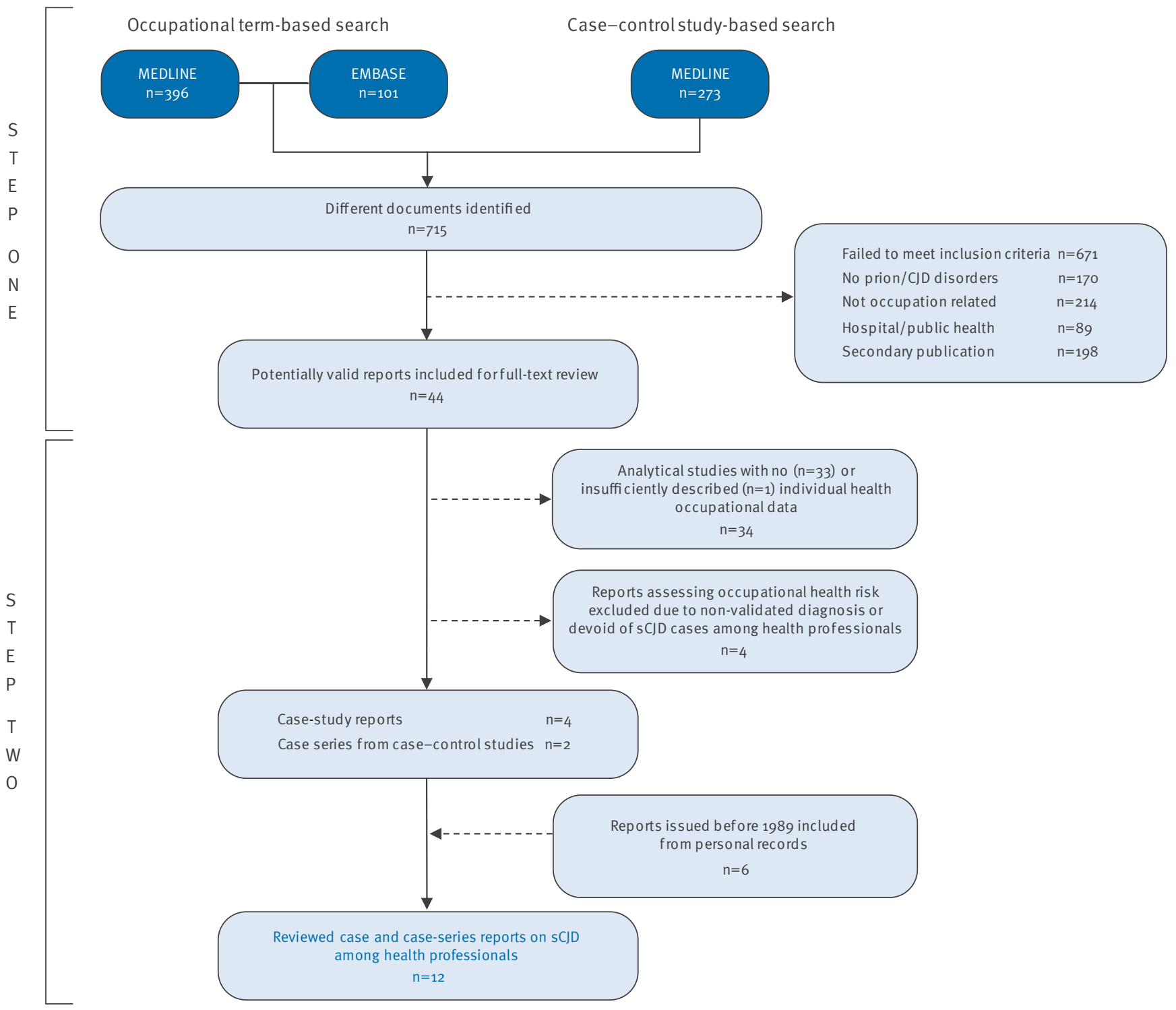




\section{FIGURE 2}

Literature review of analytical studies on occupational risk of sporadic Creutzfeldt-Jakob disease for health professionals, 1982-1 October 2011

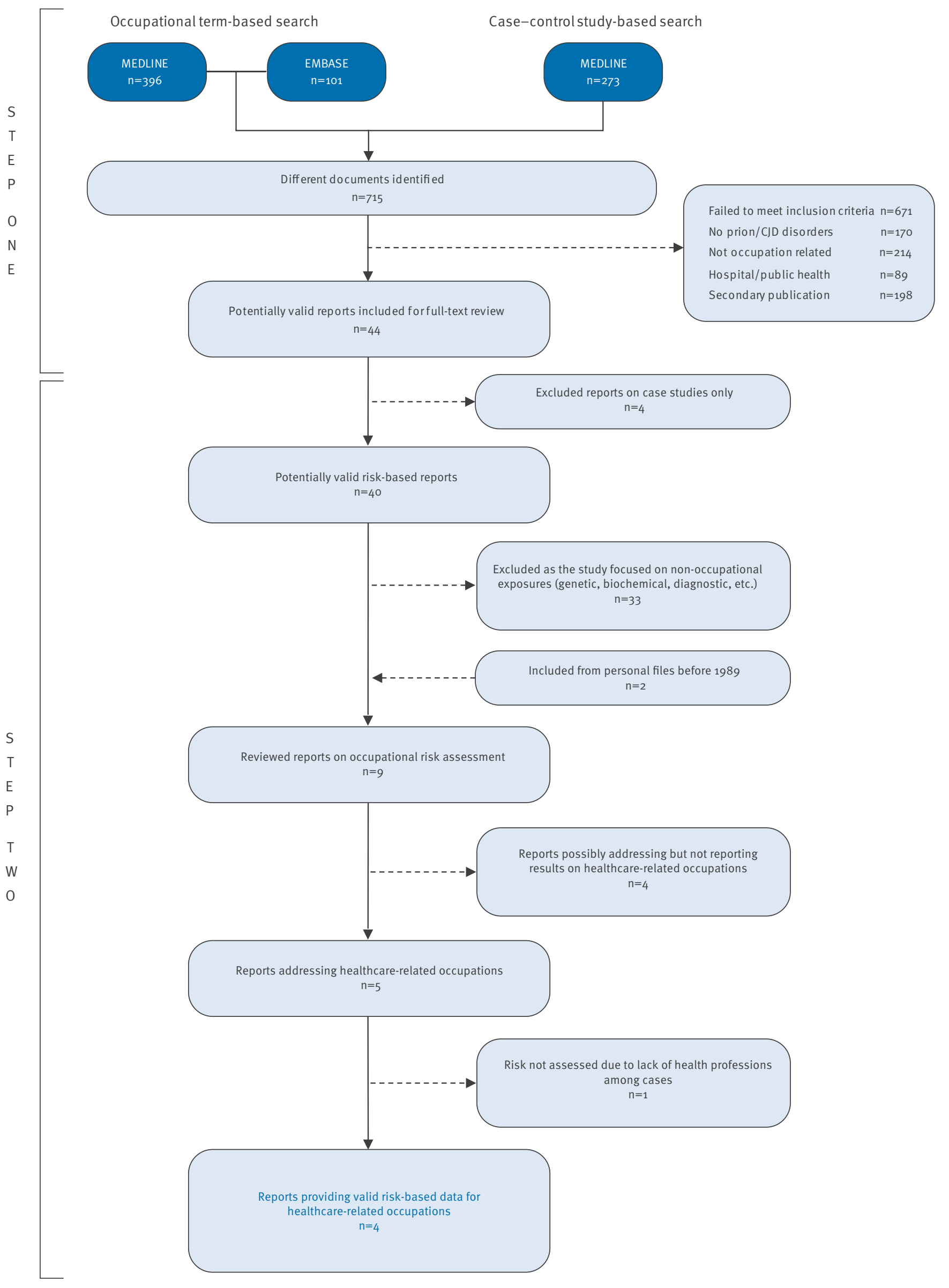

SCJD: sporadic Creutzfeldt-Jakob disease. 
analytical studies on occupational risk of CJD for health professions. The initial searches yielded a total of 715 different documents.

In a second step, two independent assessors applied predefined sets of inclusion and exclusion criteria (Box) to the titles of the retrieved documents or, where available, to their abstracts.

Documents that met the inclusion criteria were processed further for full-text analysis in order to obtain the case description or to assess health-related occupational risk of SCJD.

After the selection criteria for had been independently, though not always unanimously, applied to the 715 documents by two reviewers, EAC and JPC, 671 were rejected and 44 selected for further analysis by both reviewers (Figures 1 and 2).

Case reports of SCJD among health professionals Of the 44 documents selected for full-text review, 34 were excluded as the studies did not examine healthrelated occupations (Figure 1). Four studies that failed to include specific categories of health professionals with SCJD or in which the diagnosis of CJD was not validated were also excluded $[3,6,7,19]$. Six studies - four case reports $[10-12,20]$ and two case-control studies, which provided information on health-related occupations in SCJD case series $[5,21]$ - were selected for data extraction. Five case studies and one case-control study retrieved from personal records before 1989 were also included $[4,8,9,17,22,23]$. Thus, the final analysis of 12 reports included data on individual health professionals from case reports $[8-12,17,20,22,23]$ and numbers of health professionals with $\mathrm{SCJD}$ from three reports on case-control studies $[4,5,21]$. These 12 reports included SCJD cases fulfilling diagnostic criteria for neuropathologically confirmed SCJD or for probable $\mathrm{SCJD}$ (people in the latter category were only included in case-control studies) $[5,24]$. Where health professions were listed in the case series of a large case-control study and numbers were not reported, only one individual, e.g. a dentist, was counted [5].

Epidemiologically assessed healthcare-

related occupational risk of sCJD

Of the 44 documents selected for full-text review (the same 44 mentioned above), 40 fulfilled the inclusion criteria. After analysis of the texts, seven analytical studies on occupation and risk of SCJD remained for potential data extraction $[3,5-7,19,21,25]$.Those excluded were multipurpose case-control investigations that made no mention of occupation in the results, occupation-unrelated meta-analyses, genetic case-control studies and public-health occupational profiles derived from empirical data. Four analytical studies reported before 1989 were reviewed: two were included $[4,26]$ and two rejected $[27,28]$. Nine documents $[3-7,19,21,25,26]$ provided data on occupational risk but only five of these addressed healthcare-related occupations $[5-7,19,26]$. Due to the low numbers (absence of exposed cases) in one study [26], riskbased data for health professions were only available from four case-control studies [5-7,19]. Reported associations for healthcare-related occupational risk obtained from these four epidemiological studies and raw negative findings from the above-mentioned study [26] were tabulated.

\section{Results}

\section{Individualised occupational data from national CJD surveillance teams}

Health professionals among registered SCJD cases

A total of 202 health professionals were listed among 8,321 cases of SCJD registered by 21 respondent countries participating in EuroCJD (Table 1). Of these, 65 (32\%) were physicians and 137 were other healthcare workers. The highest numbers by medical speciality were general practitioners $(n=9)$, surgeons $(n=7)$, internists $(n=7)$, dentists $(n=4)$, ophthalmologists $(n=3)$ and pathologists $(n=2)$. The proportion of physicians or dentists among all registered SCJD cases was $65 / 8,321$ (o.8\%).

Health professionals among non-cases or controls Table 2 shows individual data reported for health professions among non-cases or controls in five countries (Germany, Italy, Japan, Spain and the UK). Among 83 healthcare workers, 15 were physicians, six of whom had unknown specialisations, and three were surgeons. The percentage of physicians and dentists among CJD cases in Germany, Italy, Japan, Spain and the UK combined was $0.7 \%(34 / 4,949$ (Table 1). This was similar to the proportion in the combined controls $0.5 \%(15 / 2,968)$.

\section{Literature reviews}

Reported SCJD in health professionals Individual occupational profiles of reported healthrelated professionals with SCJD are outlined in Table 3. The data are derived from 12 studies, three of which were case-control studies. In these 12 studies, a total of 66 health workers with SCJD were reported, at least eight of whom were physicians $[4,5,8-12,17,20$ 23]. One report described genetic CJD with phenotype resembling SCJD in three Slovakian health workers (two nurses and one dermatologist) with a mutation in codon 200 of the PRNP gene [11].

The following professions have been reported in SCJD cases: dentists $(n=5)$, dental surgeon $(n=1)$, neurosurgeons $(n=2)$, pathologist $(n=1)$, internist with training in pathology $(n=1)$ and orthopaedic surgeon who had worked with sheep and human dura mater for industrial purposes $(n=1)$ [12]. The majority of the remaining health professionals were nurses, two of whom had worked in neurosurgery and neurological care. Two other workers had been or were technicians at pathology laboratories. 
TABLE 1

Occupational profile of sporadic Creutzfeldt-Jakob disease cases reported to the European Creutzfeldt Jakob Disease

Surveillance Network (EuroCJD), 1965-2010 (n=8,321)

\begin{tabular}{|c|c|c|c|c|c|c|c|c|c|c|c|c|c|c|c|c|c|c|c|c|c|c|}
\hline \multirow[t]{3}{*}{ Occupation } & \multicolumn{22}{|c|}{ Number of SCJD cases, by countrya, in the specified time period } \\
\hline & $\stackrel{\alpha}{<}$ & ঔ & ६ & 岗 & $\varangle$ & 乙 & 吕 & $\stackrel{\propto}{4}$ & 㟔 & 코 & $=$ & $上$ & $\cong$ & $\vec{z}$ & \llcorner & 学 & $\vec{n}$ & 㞻 & 虫 & I & 弚 & \\
\hline & $\begin{array}{l}0 \\
0 \\
0 \\
1 \\
\infty \\
\infty \\
o \\
0\end{array}$ & 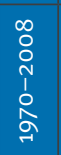 & 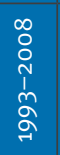 & 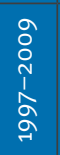 & $\begin{array}{l}a \\
0 \\
0 \\
i \\
1 \\
\infty \\
o \\
a \\
\sigma\end{array}$ & 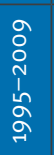 & $\begin{array}{l}\text { oे } \\
0 \\
\hat{1} \\
1 \\
\text { aे } \\
\text { aे }\end{array}$ & 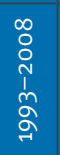 & 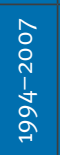 & 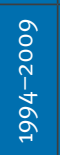 & 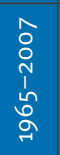 & 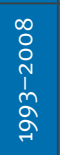 & 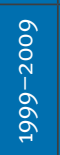 & $\begin{array}{l}\infty \\
0 \\
0 \\
N \\
1 \\
n \\
o \\
\sigma\end{array}$ & $\begin{array}{l}a \\
0 \\
0 \\
1 \\
1 \\
o \\
\sigma \\
\sigma\end{array}$ & $\begin{array}{l}0 \\
\stackrel{0}{0} \\
\hat{N} \\
1 \\
0 \\
\stackrel{-}{a} \\
\stackrel{-}{2}\end{array}$ & $\begin{array}{l}a \\
0 \\
0 \\
1 \\
1 \\
\infty \\
\infty \\
0 \\
-1\end{array}$ & $\begin{array}{l}a \\
0 \\
o \\
1 \\
n \\
o \\
o \\
\sigma\end{array}$ & $\begin{array}{l}\hat{o} \\
0 \\
\hat{N} \\
1 \\
\hat{a} \\
\text { aे }\end{array}$ & 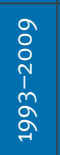 & $\begin{array}{l}0 \\
0 \\
0 \\
1 \\
1 \\
0 \\
0 \\
0 \\
0\end{array}$ & ๘ँ \\
\hline \multicolumn{23}{|l|}{ Physicians or dentists } \\
\hline Cardiovascular surgeon & o & o & o & - & - & - & - & - & 0 & 0 & o & 0 & 1 & 0 & 0 & 0 & 0 & 0 & - & 0 & 0 & 1 \\
\hline Surgeon/urologist & 1 & 0 & 0 & - & - & - & - & - & 1 & 0 & 0 & 0 & 0 & 0 & 0 & 0 & 0 & 0 & - & 0 & 0 & 2 \\
\hline Surgeon and neuropathologist & 0 & 0 & 0 & - & - & - & - & - & 1 & 0 & 0 & 0 & 0 & 0 & 0 & 0 & 0 & 0 & - & 0 & 0 & 1 \\
\hline Traumatologist/surgeon & 1 & 0 & 0 & - & - & - & - & - & 0 & 0 & 0 & 0 & 0 & 0 & 0 & 0 & 0 & 0 & - & 0 & 0 & 1 \\
\hline Ophthalmologist & 0 & 0 & 0 & - & - & - & - & - & 0 & 1 & 0 & 1 & 0 & 0 & 0 & 0 & 0 & 1 & - & 0 & 0 & 3 \\
\hline Surgeon (not specified) & 0 & 0 & 0 & - & - & 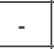 & - & - & 0 & 0 & 0 & 0 & 0 & 0 & 0 & 0 & 0 & 1 & - & 0 & 0 & 1 \\
\hline Pathologist & 0 & 0 & 0 & 0 & 0 & 0 & 0 & 0 & 0 & 0 & 0 & 0 & 0 & 0 & 0 & 0 & 0 & 1 & 0 & 0 & 0 & 1 \\
\hline Neuropathologist's assistant & 0 & 0 & 0 & - & - & - & - & - & 1 & 0 & 0 & 0 & 0 & 0 & 0 & 0 & 0 & 0 & - & 0 & 0 & 1 \\
\hline Forensic medicine & 0 & 0 & 0 & - & - & - & - & - & 0 & 0 & 0 & 1 & 0 & 0 & 0 & 0 & 0 & 0 & - & 0 & 0 & 1 \\
\hline Dentist & 1 & o & 1 & - & - & - & - & - & 0 & 0 & 2 & 0 & 0 & 0 & 0 & 0 & 0 & 0 & - & 0 & 0 & 4 \\
\hline Traumatologist & 1 & 0 & 0 & - & - & - & - & - & 0 & 0 & 0 & 0 & 0 & 0 & 0 & 0 & 0 & 0 & - & 0 & 0 & 1 \\
\hline Plastic surgeon & 0 & 0 & 0 & - & - & - & - & - & 0 & 0 & 0 & 0 & 0 & 0 & 0 & 0 & 0 & 1 & - & 0 & 0 & 1 \\
\hline Paediatrics/anatc & 0 & 0 & 0 & - & - & - & - & - & 0 & 0 & 0 & 0 & 0 & 0 & 0 & 0 & 0 & 0 & - & 0 & 1 & 1 \\
\hline Cardiologist & 0 & 1 & 0 & - & - & - & - & - & 0 & 0 & 0 & 0 & 0 & 0 & 0 & 0 & 0 & 0 & - & 0 & 0 & 1 \\
\hline Internist & 0 & 0 & 2 & - & - & - & - & - & 2 & 0 & 0 & 3 & 0 & 0 & 0 & 0 & 0 & 0 & - & 0 & 0 & 7 \\
\hline Clinical oncologist & 1 & 0 & 0 & - & - & - & - & - & 0 & 0 & 0 & 0 & 0 & 0 & 0 & 0 & 0 & 0 & - & 0 & 0 & 1 \\
\hline Toxicologist & 0 & 1 & 0 & - & - & - & - & - & 0 & 0 & 0 & 0 & 0 & 0 & 0 & 0 & 0 & 0 & - & 0 & 0 & 1 \\
\hline General practitioner & 0 & 3 & 0 & - & - & - & - & - & 0 & 0 & 1 & 3 & 0 & 0 & 0 & 0 & 0 & 1 & - & 0 & 1 & 9 \\
\hline Psychiatrist & 0 & 0 & 0 & - & - & - & - & - & 0 & 0 & 0 & 0 & 1 & 0 & 0 & 0 & 0 & 0 & - & 0 & 0 & 1 \\
\hline Paediatrician & 1 & 0 & 0 & - & - & - & - & - & 0 & 0 & 0 & 0 & 0 & 0 & 0 & 0 & 0 & 0 & - & 0 & 0 & 1 \\
\hline Radiologist & 0 & 0 & 0 & - & - & - & - & - & 0 & 0 & 0 & 0 & 0 & 0 & 0 & o & o & 0 & - & 0 & 1 & 1 \\
\hline Scientist & 0 & 0 & 0 & - & - & - & - & - & 0 & 1 & 0 & 0 & 0 & 0 & 0 & 0 & 0 & 0 & - & 0 & 0 & 1 \\
\hline National service medical corps & 0 & 0 & 0 & - & - & - & - & - & 0 & 0 & 0 & 0 & 0 & 0 & 0 & 0 & 0 & 0 & - & 0 & 1 & 1 \\
\hline Alternative medical practitioner & 0 & 0 & 0 & - & - & - & - & - & 2 & 0 & 0 & 0 & 0 & 0 & 0 & 0 & 0 & 0 & - & 0 & 0 & 2 \\
\hline Epidemiologist & 0 & 0 & 0 & - & - & - & - & - & 0 & 0 & 0 & 0 & 0 & 0 & 0 & 1 & 0 & 0 & - & 0 & 0 & 1 \\
\hline Geriatrician & o & 0 & 0 & - & - & - & - & - & 0 & 0 & 1 & 0 & 0 & 0 & 0 & 0 & 0 & 0 & - & 0 & 0 & 1 \\
\hline Virologist & 0 & 0 & 0 & - & - & - & - & - & 0 & 0 & 1 & 0 & 0 & 0 & 0 & 0 & 0 & 0 & - & 0 & 0 & 1 \\
\hline Other (specialisation not specified) & 0 & 0 & 0 & - & - & - & - & 9 & 0 & 0 & 0 & 4 & 0 & 0 & 0 & 0 & 0 & 4 & - & 0 & 0 & 17 \\
\hline $\begin{array}{l}\text { Number of } s C J D \text { cases } \\
\text { among physicians or dentists }\end{array}$ & 6 & 5 & 3 & - & - & - & - & 9 & 7 & 2 & 5 & 12 & 2 & 0 & o & 1 & o & 9 & - & o & 4 & 65 \\
\hline \multicolumn{23}{|l|}{ Other health professionals } \\
\hline Laboratory technician & 0 & - & 0 & - & - & - & - & - & - & 0 & 0 & 1 & 1 & 1 & - & 0 & 0 & - & - & - & 2 & 5 \\
\hline Sterilisation department & 0 & - & 0 & - & - & - & - & - & - & 0 & 0 & 0 & 0 & 1 & - & 0 & 0 & - & - & - & 0 & 1 \\
\hline Veterinarian & 1 & - & 0 & - & - & - & - & - & - & $1^{\mathrm{b}}$ & 0 & 1 & 0 & 0 & - & 0 & 0 & - & - & - & 0 & 3 \\
\hline Hospital employee & 1 & - & 0 & - & - & - & - & - & - & 0 & 0 & 2 & 0 & 0 & - & 0 & 0 & - & - & - & 5 & 8 \\
\hline Other & 0 & - & 0 & - & - & - & - & - & - & $1^{\mathrm{b}}$ & 0 & 17 & 17 & 0 & - & 2 & 2 & - & - & - & 45 & 84 \\
\hline $\begin{array}{l}\text { Number of SCJD cases among all } \\
\text { other health professionals }\end{array}$ & 2 & - & 0 & - & - & - & - & 36 & - & 2 & 0 & 21 & 18 & 2 & - & 2 & 2 & - & - & - & 52 & 137 \\
\hline $\begin{array}{l}\text { Number of } S C J D \text { cases among all } \\
\text { healthcare professionals }\end{array}$ & 8 & 5 & 3 & - & - & - & - & 45 & 7 & 4 & 5 & 33 & 20 & 2 & - & 3 & 2 & 9 & - & - & 56 & 202 \\
\hline $\begin{array}{l}\text { Total number of } \\
\text { registered SCJD cases }\end{array}$ & $\begin{array}{l}\text { iे } \\
\text { : }\end{array}$ & $\hat{\circ}$ & $:$ & 車 & 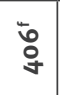 & a & $\begin{array}{l}\infty \\
\infty \\
\infty\end{array}$ & 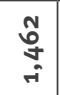 & 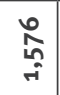 & $\stackrel{f}{\mathcal{F}}$ & $\stackrel{m}{m}$ & 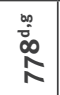 & $\tilde{\varkappa}$ & $\stackrel{n}{n}$ & na & 市 & $\stackrel{c}{\infty}$ & $m_{\infty}^{m}$ & $\stackrel{5}{n=0}$ & 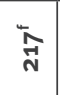 & $\stackrel{\substack{N \\
N}}{\infty}$ & $\underset{\infty}{\stackrel{N}{m}}$ \\
\hline
\end{tabular}

$\mathrm{AR}=$ Argentina, $\mathrm{AU}=$ Australia, $\mathrm{AT}=$ Austria, $\mathrm{BE}=\mathrm{Belgium}, \mathrm{CA}=\mathrm{C}$ anada. $\mathrm{CY}=\mathrm{Cypus}, \mathrm{DK}=$ Denmark, $\mathrm{FR}=\mathrm{France}, \mathrm{DE}=\mathrm{Germany}, \mathrm{HU}=\mathrm{Hung}$ ary, $\mathrm{IL}=\mathrm{ISrael}, \mathrm{IT}=\mathrm{Italy}$, $\mathrm{JP}=$ Japan, NL=Netherlands, $\mathrm{PT}=$ Portugal, SK=Slovakia,SL=Slovenia, ES=Spain, SE=Sweden, $\mathrm{CH}=\mathrm{Switzerland}$, UK=United Kingdom.

SCJD: sporadic Creutzfeldt-Jakob disease. The dashes represent years for which there are no data.

a There were no reports of SCJD among Polish pathologists, clinicians or medical technicians (personal communication, Dr J. Kulczycki, May 2009)./ b The two (non-medical) health workers were pathology assistants./ ' Data for countries reporting presence versus absence of sCJD among pathologists

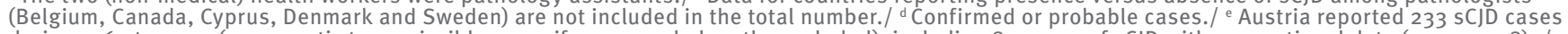
during 1969 to 2009 (one genetic transmissible spongiform encephalopathy excluded), including 84 cases of sCJD with occupational data (1993-2008). / f SCJD deaths obtained from the EuroCJD website [16]. Otherwise different categories of registered sCJD on request./ ${ }^{\mathrm{g}} \mathrm{SCJD}$ cases with occupational data only./ h Occupational data not registered. 
Only one of three case-control studies $[4,5,21]$ provided data on specialities but gave no indication of the numbers involved [5]. It is likely that most cases mentioned in the EuroCJD study by Van Duijn et al. [5] were included in country-specific occupational counts of the case set obtained from the extended EuroCJD consortium in response to the current request.

\section{Health-related occupational risk of sCJD}

The nine analytical papers on occupations and SCJD identified $[3-7,19,21,25,26]$ tended to focus on healthcare and animal care-related occupations, with Cocco et al.'s study furnishing detailed data on other occupations [19]. This study used a large number of non-validated CJD diagnoses from death records in the United States and controls selected after exclusion of persons with neurological diseases reported as the cause of death [19]. The main findings for healthcare-related occupations from five papers are summarised in Table 4. While three of four studies on health professions did not demonstrate excess risk [5-7], statistically significant findings - for persons working at physicians' offices - were solely reported by Cocco et al. [19].

\section{Discussion}

Despite a number of case reports of $\mathrm{SCJD}$ in physicians and technicians, the findings of this EuroCJD survey do not suggest an increased risk of $\mathrm{SCJD}$ in health professionals, nor do analytical studies show a clear excess risk for health-related professions. Methodological limitations of analytical studies in which occupational data were frequently provided by informants who were probably aware of the SCJD diagnosis [3-7,26] argue in favour of a cautious interpretation of the positive association reported for persons working at physicians' offices [19]. Consequently, the main finding of this literature review and complementary EuroCJD observation is that health professionals, including medical staff, are not at greater risk of developing SCJD. However, this cannot exclude the possibility that there may be an occupational risk in specific circumstances, for example, for people in contact with high-risk central nervous system tissue, and appropriate precautions, as recommended by national authorities, should therefore be followed, particularly regarding laboratory work.

Although in some studies occupation was specifically analysed $[19,25]$ and occupation may be the subject of specific inquiry in some surveillance systems, a limitation of some registries and scientific studies is that occupation may not have been systematically recorded. When occupation was recorded, it is unlikely that a framework for consistent occupational data collection was used, so that neither registries nor case-control studies have incorporated the classic epidemiological double approach. Recording of occupation may not identify specific chemical or biological exposures, which would require data for professions (job titles, medical specialisations) being cross-referenced with branches of activity (laboratory, administrative or clinical patient-contact work). The lack of registered surveillance data that combine profession with activity (e.g. contact with human tissue), when compared with the descriptions from previous case reports and the incident in Spain, illustrates the limits of the validity of available data for analytical purposes and precludes formal use of statistical testing. Although our study does not provide evidence of an excess risk of SCJD in health professionals, the fact that the data collected were mainly linked to medical speciality rather than actual activity might have concealed an excess risk of SCJD for some specific health professionals.

A case-control study seeking to examine the putative occupational risk posed by surgical injuries should have a biologically clear working hypothesis and a custom-tailored methodology. Matrices designed by linking medical speciality and surgical/forensicanatomical/pathological activity, in which the health

\section{TABLE 2}

Occupational profile of non-cases or controls obtained through the European Creutzfeldt Jakob Disease Surveillance Network (EuroCJD), 1980-2009 (n=2,968)

\begin{tabular}{|c|c|c|c|c|c|c|}
\hline \multirow[t]{3}{*}{ Occupation } & \multicolumn{6}{|c|}{$\begin{array}{c}\text { Number of professionals, } \\
\text { by country, in the } \\
\text { specified time period }\end{array}$} \\
\hline & 㟔 & $\models$ & $\cong$ & 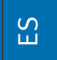 & 兰 & \\
\hline & 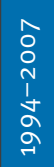 & 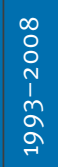 & $\begin{array}{l}a \\
\circ \\
o \\
1 \\
1 \\
2 \\
\text { aे }\end{array}$ & $\begin{array}{l}a \\
\circ \\
0 \\
N \\
1 \\
m \\
o \\
o \\
-1\end{array}$ & 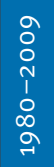 & 흉 \\
\hline \multicolumn{7}{|l|}{ Physicians } \\
\hline Traumatologist/surgeon & 0 & 1 & 0 & 0 & 0 & 1 \\
\hline Surgeon (not specified) & 0 & 1 & 0 & 0 & 1 & 2 \\
\hline Internist & 0 & 1 & 0 & 0 & 0 & 1 \\
\hline General practitioner & 0 & 1 & 0 & 0 & 1 & 2 \\
\hline Psychiatrist & 0 & 0 & 0 & 1 & 0 & 1 \\
\hline Paediatrician & 1 & 0 & 0 & 0 & 0 & 1 \\
\hline Scientist & 0 & 0 & 0 & 0 & 1 & 1 \\
\hline Other (specialisation not specified) & 6 & 0 & 0 & 0 & 0 & 6 \\
\hline Number of physicians & 7 & 4 & 0 & 1 & 3 & 15 \\
\hline \multicolumn{7}{|l|}{ Other health professionals } \\
\hline Laboratory technician & - & 2 & - & - & 5 & 7 \\
\hline Hospital employee & - & 1 & - & - & 13 & 14 \\
\hline Other & - & 10 & - & - & 34 & 44 \\
\hline $\begin{array}{l}\text { Number of other health } \\
\text { professionals }\end{array}$ & - & 13 & 3 & - & 52 & 68 \\
\hline Number of healthcare professionals & 7 & 17 & 3 & 1 & 55 & 83 \\
\hline $\begin{array}{l}\text { Total number of } \\
\text { non-cases or controls }\end{array}$ & 范 & 总 & $\underset{\infty}{\infty}$ & $\widehat{\widehat{\sigma}}$ & 疍 & $\begin{array}{l}\infty \\
\vdots \\
\alpha \\
\text { ì }\end{array}$ \\
\hline
\end{tabular}

$D E=G e r m a n y ; I T=I t a l y$; JP=Japan; ES=Spain; UK=United Kingdom.

The dashes represent years for which there are no data.

a Controls from own case-control study.

Only persons with occupational data. 
professional can come into direct contact with high human-infectivity tissue by accident might not provide a sufficient background for analysis, without appropriate control being made for the influence of PRNP genotype, surgical or laboratory work history and long latency. Assuming that among non-cases or controls the proportion of medical specialities with potential exposure (surgeons, forensic surgeons and other surgical specialists, pathologists) may be low, i.e. approximately 1 per 1,000 (based on the figures of 3/2,968 in Table 2), the study size that would afford the necessary statistical power for a proper examination of the specific practices of health professions is higher than that provided by existing CJD registries in any one country. Since complementary analyses would be needed for professional and activity categories defined in terms of temporal references that have not been explored to date, such as 'ever employed' or 'currently employed', as well as duration of employment, requirements for study size and collaboration would be even higher.

\section{TABLE 3}

Health-profession-related sporadic Creutzfeldt-Jakob disease case reports from literature review,

1979-1 October 2011

\begin{tabular}{|c|c|}
\hline Number of cases and their professions & Source \\
\hline $\begin{array}{l}3 \text { dentists } \\
1 \text { neurosurgeon } \\
1 \text { dental surgeon } \\
6 \text { nurses } \\
1 \text { assistant nurse }\end{array}$ & [17] \\
\hline 1 neurosurgeon & [23] \\
\hline $\begin{array}{l}3 \text { nurses } \\
2 \text { assistant nurses }\end{array}$ & {$[22]$} \\
\hline 1 histopathology technician & {$[8]$} \\
\hline 1 histopathology technician & [9] \\
\hline $\begin{array}{l}1 \text { physician } \\
1 \text { dentist } \\
3 \text { career nurses } \\
2 \text { people with brief nursing experience }\end{array}$ & {$[4]^{\mathrm{a}}$} \\
\hline 1 pathologist & [20] \\
\hline $\begin{array}{l}1 \text { internist, formally trained in pathology } 30 \text { years } \\
\text { previously }\end{array}$ & {$[10]$} \\
\hline $\begin{array}{l}1 \text { orthopaedic surgeon handling sheep and human } \\
\text { dura mater } 20-25 \text { years before symptom onset }\end{array}$ & {$[12]$} \\
\hline $\begin{array}{l}32 \text { cases that included a physician; } \\
\text { neuropathologist; nurse; laboratory technician; } \\
\text { dentist and ambulance worker }\end{array}$ & {$[5]^{\mathrm{a}}$} \\
\hline 1 nurse, gastrointestinal section & {$[21]^{\mathrm{a}}$} \\
\hline $\begin{array}{l}1 \text { nurse and } 1 \text { ambulance driver without E200 } \\
\text { mutation } \\
2 \text { nurses, } 1 \text { physician (dermatologist) with } \\
\text { sporadic-like forms, carriers of E200K mutation } \\
1 \text { nurse (not from Slovakia. where the cases were } \\
\text { reported), genotyping not done }\end{array}$ & {$[11]^{\mathrm{b}}$} \\
\hline
\end{tabular}

a Described in case-control studies and, in general, fulfilling criteria as probable or confirmed sporadic Creutzfeldt-Jakob disease (SCJD) $[17,24]$.

Mention of clinical features, genetic study or country of origin is frequently made in Slovakian cases given the high incidence of genetic forms and the relevance of genotyping for correct classification of CJD.
In conclusion, a wide spectrum of medical specialities and health professions are represented in SCJD registries. Although selection due to higher ascertainment may lie behind the case reports of certain professions involved in clinical management or care of patients with SCJD, the biological significance of these observations remains uncertain and available data do not indicate an increased risk of SCJD in health professionals. However, the methodological issues mentioned above indicate the need for caution in drawing conclusions from the data and large-scale studies with specific causal hypotheses are needed in order for further research to be undertaken into the potential link between health professions and SCJD

\section{.Acknowledgments}

The authors would like to thank all EuroCJD network members and officials worldwide who furnished data constituting and/or comments contributing to the basis of this study, and the following in particular: Prof. P. Cras, Belgium; Dr G. Jansen, Canada; Mrs G. Klug, Australia; Drs K. Mølbak and H. Laursen, Denmark; Dr S. Papacostas, Cyprus; Dr J. Kulczycki, Poland; Mrs F. Avellanal, Spain; Dr A. L. Hammarin and Mrs S. Ivarsson, Sweden; and Dr R. Knight, United Kingdom.

The EuroCJD network has been supported by DirectorateGeneral for Research and Innovation (DG Research), Directorate-General for Health and Consumers (DG SANCO) and the European Centre for Disease Prevention and Control.

\section{References}

1. Prusiner SB. The prion diseases. Brain Pathol. 1998;8(3):499-513.

2. Ladogana A, Puopolo M, Croes EA, Budka H, Jarius C, Collins $\mathrm{S}$, et al. Mortality from Creutzfeldt-Jakob disease and related disorders in Europe, Australia, and Canada. Neurology. 2005;64(9):1586-91.

3. Collins S, Law MG, Fletcher A, Boyd A, Kaldor J, Masters CL. Surgical treatment and risk of sporadic Creutzfeldt-Jakob disease: a case-control study. Lancet. 1999;353(9154):693-7.

4. Harries-Jones R, Knight R, Will RG, Cousens S, Smith PG, Matthews WB. Creutzfeldt-Jakob disease in England and Wales, 1980-1984: a case-control study of potential risk factors. J Neurol Neurosurg Psychiatry. 1988;51(9):1113-9.

5. van Duijn CM, Delasnerie-Lauprêtre N, Masullo C, Zerr I, de Silva R, Wientjens DP, et al. Case-control study of risk factors of Creutzfeldt-Jakob disease in Europe during 1993-95. European Union (EU) Collaborative Study Group of CreutzfeldtJakob disease (CJD) Lancet. 1998;351(9109):1081-5.

6. Wientjens DP, Davanipour Z, Hofman A, Kondo K, Matthews WB, Will RG, et al. Risk factors for Creutzfeldt-Jakob disease: a reanalysis of case-control studies. Neurology. 1996;46(5):1287-91.

7. Ruegger J, Stoeck K, Amsler L, Blaettler T, Zwahlen M, Aguzzi A, et al. A case-control study of sporadic Creutzfeldt-Jakob disease in Switzerland: analysis of potential risk factors with regard to an increased CJD incidence in the years 2001-2004. BMC Public Health. 2009;9:18.

8. Miller DC. Creutzfeldt-Jakob disease in histopathology technicians [letter]. N Engl J Med. 1988;318(13):853-4.

9. Sitwell L, Lach B, Atack E, Atack D, Izukawa D. CreutzfeldtJakob disease in histopathology technicians [letter]. N Engl ] Med. 1988;318(13):854.

10. Berger JR, David NJ. Creutzfeldt-Jakob disease in a physician: a review of the disorder in health care workers. Neurology. 1993;43(1):205-6.

11. Mitrová E, Belay G. Creutzfeldt-Jakob disease in health professionals in Slovakia. Eur J Epidemiol. 2000;16(4):353-5.

12. Weber T, Tumani H, Holdorff B, Collinge J, Palmer $M$, Kretzschmar HA, et al. Transmission of Creutzfeldt Jakob disease by handling of dura mater. Lancet. 1993;341(8837):123-4. 
TABLE 4

Summary of methods and main results of analytical epidemiological research into healthcare-related occupations and sporadic Creutzfeldt-Jakob disease, literature review, 1982-1 October 2011

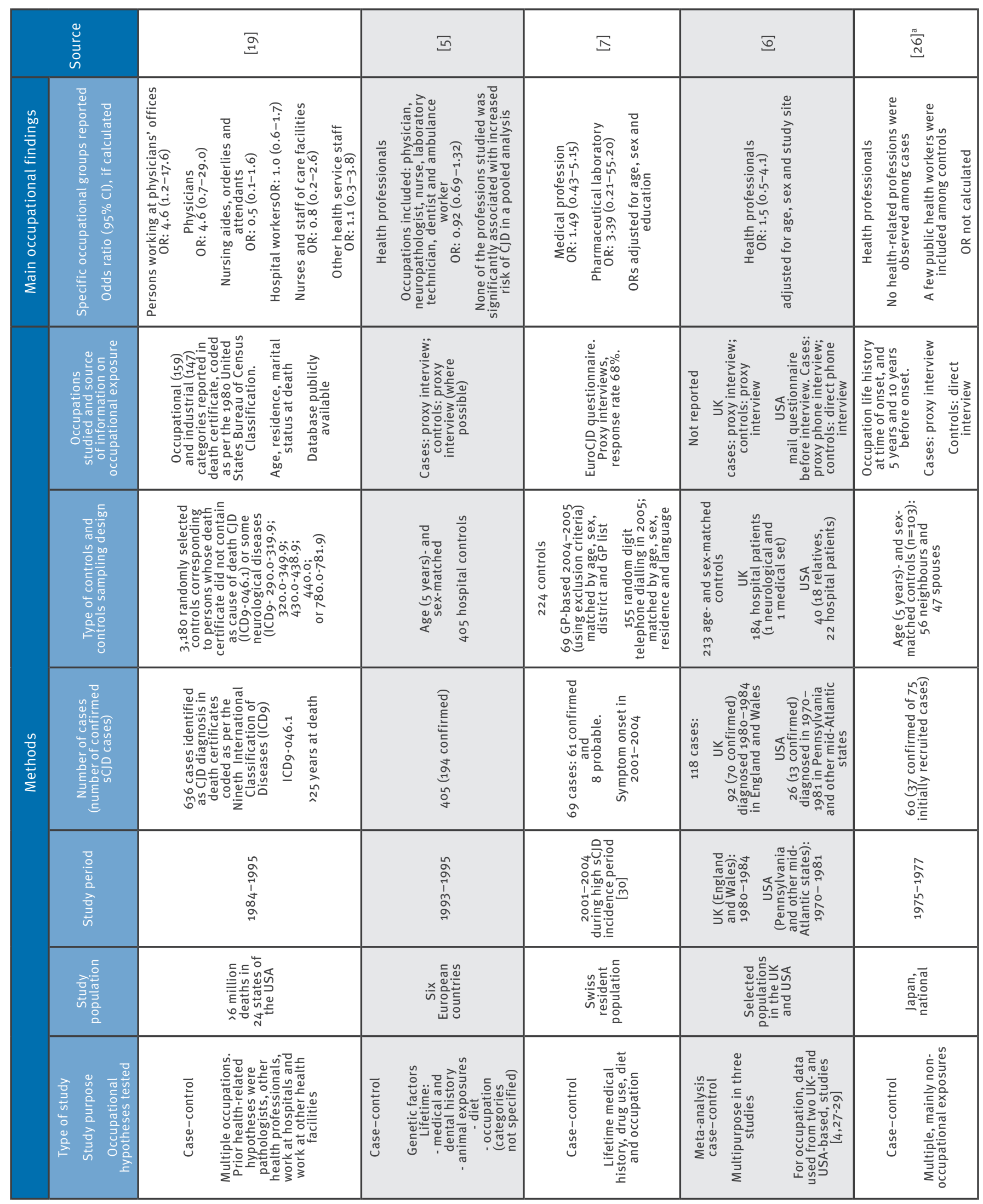

CJD: Creutzfeldt-Jakob disease; EuroCJD: European Creutzfeldt Jakob Disease Surveillance Network; GP: general practitioner; OR: odds ratio UK: United Kingdom; USA: United States of America.

${ }^{\text {a }}$ The information on health-related occupations from this study was not included in the meta-analysis [6]. 
13. Neeleman E, Molhoek R. CJD-NQUEST manual. Data entry sofware for CJD-surveillance. Rotterdam: Department of Epidemiology and Biostatistics, Erasmus University; 1998.

14. European Centre for Disease Prevention and Control (ECDC). Review of guidelines for prevention of Creutzfeldt-Jakob disease transmission in medical settings in EU Member States and Norway. Stockholm: ECDC; 2011.

15. Terry S. Singeltary Sr. Doctor Antonio Ruiz Villaespesa, pathologist and CJD researcher deceased because of Creutzfeldt-Jakob Disease SPAIN. 21 Apr 2009. [Accessed 11 Apr 2012]. In: Monitoring the occurrence of emerging forms of CJD [blog]. Available from: http://cjdusa.blogspot.com. es/2009/04/doctor-antonio-ruiz-villaespesa.html

16. The European Creutzfeldt Jakob Disease Surveillance Network. EUROCJD. [Accessed 11 Apr 2012]. Available from: http://www. eurocjd.ed.ac.uk/index.htm

17. Masters CL, Harris JO, Gajdusek DC, Gibbs CJ Jr, Bernoulli C, Asher DM. Creutzfeldt-Jakob disease: patterns of worldwide occurrence and the significance of familial and sporadic clustering. Ann Neurol. 1979;5(2):177-88.

18. Zerr I, Pocchiari M, Collins S, Brandel JP, de Pedro Cuesta J, Knight RS, et al. Analysis of EEG and CSF 14-3-3 proteins as aids to the diagnosis of Creutzfeldt-Jakob disease. Neurology. 2000;55(6):811-5.

19. Cocco PL, Caperna A, Vinci F. Occupational risk factors for the sporadic form of Creutzfeldt-Jakob disease. Med Lav. 2003;94(4):353-63.

20. Gorman DG, Benson DF, Vogel DG, Vinters HV. CreutzfeldtJakob disease in a pathologist. Neurology. 1992;42(2):463.

21. Nakamura Y, Oki I, Tanihara S, Ojima T, Yanagawa H, Kitamoto T, et al. A case-control study of Creutzfeldt-Jakob disease in Japan: transplantation of cadaveric dura mater was a risk factor. J Epidemiol. 2000;10(6):399-402.

22. Brown P, Cathala F, Raubertas RF, Gajdusek DC, Castaigne P. The epidemiology of Creutzfeldt-Jakob disease: conclusion of a 15-year investigation in France and review of the world literature. Neurology. 1987;37(6):895-904.

23. Schoene WC, Masters CL, Gibbs CJ Jr, Gajdusek DC, Tyler HR, Moore FD, et al. Transmissible spongiform encephalopathy (Creutzfeldt-Jakob disease). Atypical clinical and pathological findings. Arch Neurol. 1981;38(8):473-7.

24. Salazar AM, Masters CL, Gajdusek DC, Gibbs CJ Jr. Syndromes of amyotrophic lateral sclerosis and dementia: relation to transmissible Creutzfeldt-Jakob disease. Ann Neurol. 1983;14(1):17-26.

25. Cousens SN, Zeidler M, Esmonde TF, De Silva R, Wilesmith JW, Smith PG, et al. Sporadic Creutzfeldt-Jakob disease in the United Kingdom: analysis of epidemiological surveillance data for 1970-96. BMJ. 1997;315(7105):389-95.

26. Kondo K, Kuroiwa Y. A case control study of Creutzfeldt-Jakob disease: association with physical injuries. Ann Neurol. 1982;11(4):377-81.

27. Davanipour Z, Alter M, Sobel E, Asher DM, Gajdusek DC. A case-control study of Creutzfeldt-Jakob disease. Dietary risk factors. Am J Epidemiol. 1985;122(3):443-51.

28. Davanipour Z, Alter M, Sobel E, Asher D, Gajdusek DC. Creutzfeldt-Jakob disease: possible medical risk factors. Neurology. 1985;35(10):1483-6.

29. Davanipour Z, Alter M, Sobel E, Asher DM, Gajdusek DC. Transmissible virus dementia: evaluation of a zoonotic hypothesis. Neuroepidemiology. 1986;5(4):194-206.

30. Glatzel M, Rogivue C, Ghani A, Streffer JR, Amsler L, Aguzzi A. Incidence of Creutzfeldt-Jakob disease in Switzerland. Lancet. 2002;360(9327):139-41. 